\title{
VALIDITAS DAN RELIABILITAS INSTRUMEN ALAT UKUR SIT UP BERBASIS TEKNOLOGI DIGITAL
}

\author{
Muhamad Sazeli Rifki ${ }^{1}$, Fiky Farma ${ }^{2}$ \\ Universitas Negeri Padang, Ilmu Keolahragaan, Padang, Indonesia \\ Universitas Negeri Padang, Ilmu Keolahragaan, Padang, Indonesia \\ msr_rifki@fik.unp.ac.id, fiky.farma085@gmail.com
}

\begin{abstract}
This study aims to create a sit-up measurement tool based on digital technology that can provide the effectiveness and efficiency of testors and testees. firstly validated by an electrical expert and a test and measurement expert. Continue the small group test of 10 people and a large group of 20 people. Based on the results of the study showed that the Digital Technology-based Sit Up Test Measure was categorized as "Good / Eligible" as a sit-up test. The results were obtained from the validation of the $88.8 \%$ good / proper electro expert and the $94 \%$ good test and measurement expert / feasible. Thus the conclusion that the Digital Technology-based Sit Up Test Measurement Tool has been declared feasible to be used for future tests and measurements both testee and testor.
\end{abstract}

Keywords: sit up test measurement tool

\begin{abstract}
Abstrak
Penelitian ini bertujuan untuk membuat alat ukur tes sit up berbasis teknologi digital yang dapat memberikan efektifitas serta efisien testor maupun testee. terlebih dahulu di validasi oleh ahli elektro dan ahli tes dan pengukuran .Di lanjutkan uji kelompok kecil 10 orang dan uji kelompok besar 20 orang .Hasil penelitian menunjukkan bahwa Alat ukur tes sit up berbasis teknologi digital. Berdasarkan hasil penelitian menunjukkan bahwa Alat Ukur Tes Sit Up berbasis Teknologi Digital di katagorikan "Baik /Layak" sabagai alat tes sit up.Hasil tersebut diperoleh dari validasi dari ahli elektro $88,8 \%$ baik/layak dan ahli tes dan pengukuran $94 \%$ baik/layak.Dengan demikian kesimpulan bahwa Alat Ukur Tes Sit Up berbasis Teknologi Digital telah dinyatakan layak digunakan untuk tes dan pengukuran yang kedepan baik testee maupun testor.
\end{abstract}

Kata Kunci: alat ukurtes sit up

\section{PENDAHULUAN}

Olahraga adalah bagian dari aktivitas sehari-hari manusia yang berguna membentuk jasmani dan rohani yang sehat. Dalam UU RI No. 3 tahun 2005 tentang Sistem Keolahragaan Nasional olahraga adalah segala kegiatan yang sistematis untuk mendorong, membina serta mengembangkan potensi jasmani dan rohani dan sosial. Khusus dalam hal tes dan pengukuran,pemanfaatan teknologi sangatlah dianjurkan dalam rangka meminimalisir kesalahan dalam pengambilan data.sehingga data yang dikumpulkan memiliki tingakat validasi tinggi. 
Kemajuan teknologi 4.0 tidak boleh menghindari dalam kehidupan ini,karna kemajuan teknologi 4.0 akan berjalan sesuia dengan kemajuan ilmu pengetahuan.Setiap inovasi diciptakan untuk kemajuan kehidupan manusia,diantaranya :memberikan kemudahan untuk melakukan aktivitas manusia.Salah satunya dalam bidang olahraga penerapan teknologi canggih dengan disiplin ilmu olahraga sebagai alat analisis dan alat ukur cabang olahraga untuk meningkatan prestasi olahraga.

Wiarto (2015:142) mengungkapan bahwa pengembangan kemampuan IPTEK menjadi salah satu faktor dominan bagi Negara manapun untuk mencerdaskan kehidupan bangsa, meningkatkan kemakmuran rakyat. Hal ini menunjukan bahwa dengan adanya teknologi masyarakat mudah mengangsek informasi apapun dengan manfaatkan jaringan internet,sehingga segala informasi dapat diakses dengan hanya genggaman smartphone.Kondisi dapat dimanfaatkan oleh insan olahraga untuk mengali ilmu pengetahuan khususnya dalam bidang olahraga agar menambah wawasan mengenai pekembangan di tingkat nasional maupun internasional.Pada dunia olahraga penerapan ilmu pengetahuan teknologi (IPTEK) saat ini sudah banyak menghasilkan produk untuk digunakan dan dimanfaatkan sebagai alat analisis olahraga sehingga meningkatkan prestasi.

Salah satu pemanfatkan teknologi sebagai alat dengan cara tes dan pengukuran.Saat melakukan tes dan pengukuran dengan mengunakan alat yang berbasis teknologi menghasilkan data tingkat validitas yang tinggi dari pada tes secara menual,setelah itu datadapat dianalisis dan disimpulkan. Dari hasil analisis mengevaluasi kekurangan mahasiswa fakultas ilmu keolahragaan, sehingga mahasiswa dapat mengetahui kekurangan atau kesalahan yang nanti dapat diperbaiki.

Untuk mengukur kekuatan otot perut dengan melakukan tes sit up.Yaitu dengan cara tidur terlentang tangan berada dibelakang kepala,kedua kaki di tekuk hingga badan naik hingga perut menyentuh bagian kaki secara berulang-ulang selama 1 menit.Tes dan pengukuran sit up masih menggunakan tes menual menggunakan stopwatch dan dihitung oleh manusia yang tidak bisa mendeteksi kesalahan gerakan pada saat melakukan tes sit up.Selain itu permasalahan yang terjadi masih banyak gerakan sit up yang masih salah misalnya badan belum menyentuh bawah tapi sudah naik lagi keatas.

Berdasarkan realita tersebut, maka munculah pemikiran-pemikiran untuk 
menciptakan serta mengembangkan instrumen sit up yang berbasis arduino dan sensor ultrasonik dengan aplikasi android sebagai media pengukuran. Tujuannya adalah agar tersedianya instrumen sit up yang mampu mengukur kekuatan otot perut tubuh manusia. Instrument yang akan dikembangkan berbasis teknologi digital menggunakan perangkat lunak (soft ware), sensor gelombang ultrasonik berbantuan arduino. Hal ini dikarenakan dalam praktek pengukuran sit up, banyak faktor yang mempengaruhinya,baik dari tester, alat ukur, dan testi. masalah utama pada penelitian ini yaitu berada pada alat ukur yang belum dan belum ada alat ukur sit up yang berbasis arduino dan sensor ultrasonik dengan aplikasi android sebagai media pengukurannya.Harapan dari pembuatan alat tes sit up dengan menggunakan sensor tersebut dapat membantu tim penguji meringankan bebannya. Serta dapat menghasilkan perhitungan yang lebih akurat.

\section{METODELOGI PENELITIAN}

Metode yang digunakan metode penelitian dan pengembangan atau dalam bahasa inggris dikenal dengan Research and Development (R\&D) sebagai metode penelitiannya karena hasil akhir penelitian ini akan menghasilkan.Penelitian Research and Development (R\&D) (Sukmadinata, 2005) mendefinisikan penelitian dan pengembangan merupakan pendekatan penelitian untuk menghasilkan produk baru atau menyempurnakan produk yang telah ada. Jadi penelitian pengembangan merupakan metode untuk menghasilkan produk tertentu atau menyempurnakan produk yang telah ada serta menguji keefektifan produk tersebut.

Menurut Sugiyono (2010:146) metode penelitian yang digunakan untuk menghasilkan produk tertentu, dan menguji keefektifan produk tersebut. Dan terdapat 10 langkah penelitian. Dalam penelitian ini hanya diadopsi 5 langkah pertama, yakni: (1) Potensi dan Masalah, (2) Teknik Pengumpulan Data,(3) Desain Produk; (4) Validitas Produk; (5) Uji coba Pemakaian.

Pertama,potensi masalah menurut sugiyono (2010:298) menyatakan bahwa "potensi adalah segala sesuatu yang bila didayagunakan akan memiliki nilai tambah,sedangkan menurut sugiyono (2010:299). Masalah adalah penyimpanan antara yang diharapkan dengan yang terjadi. Dalam penelitian ini menemukan permasalahan dalam proses pengetesan masih manual, menghadalkan kemampuan kasat mata dan stopwatch sehingga tingkat kesalahan masih tinggi.Selain itu permasalahn yang terjadi masih banyak gerakan sit up yang masih salah misalnya 
badan belum menyentuh bawah tepi sudah naik lagi keatas. Dari permasalahan tersebut peneliti ingin mencoba mengembangakan alat ukur tes sit up berbasis teknologi digital.

Kedua,pada tahap ini teknik pengumpulan data yang di gunakan teknik observasi peneliti terlibat dangan kegiatan mata kuliah tes dan pengukuran di fakultas ilmu keolahragaan Universitas Negeri Padang.Langkah pertama yaitu dilakukan penentuan populasi yang nantinya akan dijadikan sampel. Kedua dilakukan uji coba alat terhadap sampel. Berikut merupakan prosedur yang dilakukan saat pengumpulan data dengan pengujian alat:

a) alat ukur tes sit up berbasis teknologi digital sesuai yang dibutuhkan.

b) Menghidupkan dan mengecek sistem sensor dan perangkatnya.

c) Penyampaian materi gerakan sit up yang benar

d) Pemanasan untuk para peserta uji coba alat.

e) Melakukan gerakan sit up

f) Mulai pengitungan otomatis oleh alat saat melakukan gerakan.

g) Penghitung dan jumlahnya akan tertera di aplikasi android sesuai dengan capaian tertentu.

Ketiga, Desain produk yang akan dihasilkan yaitu berupa meja sit up yang dilengkapi dengan timer, dua sensor ultrasonik dan aplikasi android. Dengan desain sebagai berikut

3

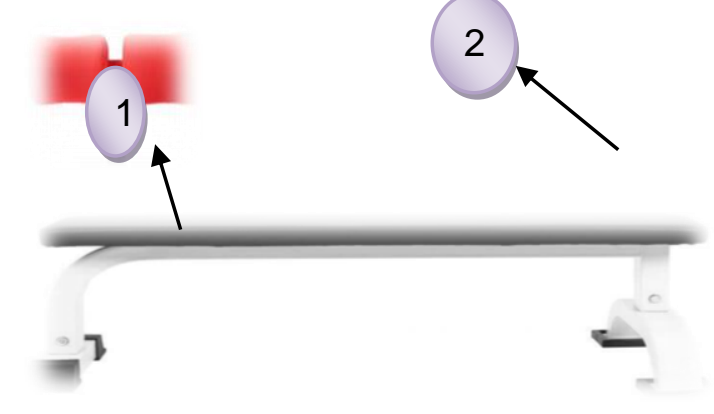

Gambar 1. rancangan meja sit up

6

4 Gamabar 2.alat ukur sit up 
Keterangan :

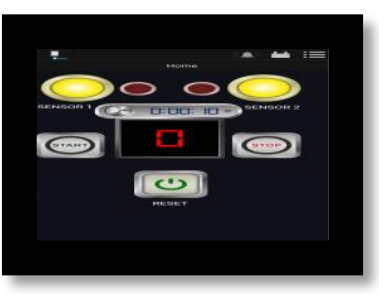

Gambar 3. Aplikasi tes sit up

1. Meja sit up

2. Penahan kaki

3. Alat ardiouno

4. Sensor ultrasonik 1

5. Sensor ultrasonik 2

6. Aplikasi tes sit up

System alat ukur ini dilihat dari desain kerasnya yaitu terdiri dari arduino,Bluetooth HC-05,sensor ultrasonik dan aplikasi android.

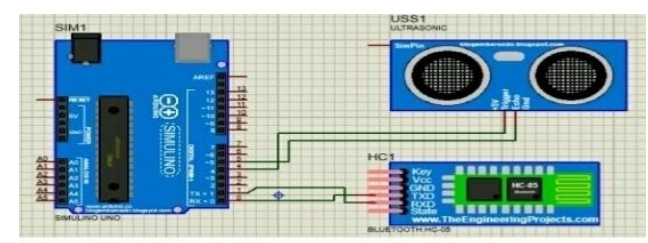

Gambar 4. rancangan rangkain alat ukur

Adapun sistem kerja yaitu sebagai berikut :

a. Instruktur menghidupkan alat ke rangkain listrik.

b. Instruktur menghidupkan bluetooth di hp android .

c. Pilih aplikasi vourtune tekan symbol bluetooth terhubung dengan arduino dan cek kedua sensor ultrasonik sudah berfungsi .

d. Tekan symbol waktu dan atur waktunya 1 menit,berikutnya tekan tombol stars.

e. Teste berbaring di meja sit up dan melakaukan gerakan sit up yaitu posisi tungkai ditekuk, kaitkan jari-jari tangan di belakang kepala,telapak kaki menepel pada penahan kaki,angkat tubuh hampir lurus vertical dan siku mengenai sensor 2,turun tubuh sampai punggung rata dangan mengenai sensor 1.Jika gerakan salah maka tidak terhitung .

f. Teste terus melakukan gerakan sit up semampunya selama 1 menit.

g. Jika waktu habis maka kedua sensor terkunci otomatis, gerakan tidak di hitung sebagi penanda rangkaian tes telah berakhir

h. Jika ingin mulai kembali instuktur menekan tombol reset, lalu menekan tombol start.

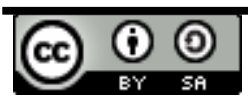

Volume 5, Nomor 1 ,Maret 2020 sportasaintika.ppj.unp.ac.id 
Keempat, validasi desain dilakukan setelah produk yang telah di desian telah selasai di buat tujuanya untuk penilaian agar dapat diketahui kekuranagan dan kekuatan dari produk.Menurut Sugiyono (2010:302) validasi desain merupakan"proses kegiatan untuk menilai apakah racanagan produk,dalam hal ini sistem kerja nasional akan lebih efektif dari yang lama atau tidak.Proses perbaikan peneiliti berdiskusi denagan pakar ahli bidang elektro dan ahli bidang tes dan pengukuran olahraga.Perbaikan ini bertujuan untuk mengurangi kekurangan sehingga menghasilkan pruduk yang berkualitas.

Kelima setelah itu uji coba pemakaian penelitian pengembangan ini,menggolongkan subjek uji coba menjadi dua adalah sebagai berikut .

1. Subjek Uji Coba Ahli

a. Ahli elektro

Ahli elektro yang dimaksud adalah dosen/pakar elektro,validasi menggunakan angket tentang menentukan apakah alat ukur tes sit up berbasis teknologi digital ini sudah sesuai.

b. Ahli Tes Dan Pengukuran

Ahli tes dan pengukuran pada penelitian ini dosen/pakar yang bisa menagani dalam hal tes dan pengukuran .Validasi menggunakan angket tentang desain alat ukur yang di berikan kepada ahli tes dan pengukuran.

2. Subjek Uji Coba

Subjek uji coba dalam penelitian pengembangan ini mahasiswa IImu Keolahragaan ,kesehatan dan rekreasi tahun 2016.Uji coba tersebut dilakukan beberapa tahap, kelompok kecil yang jumlah 10 orang sampel dan kelompok besar.yang jumlah 20 orang sampel.

\section{Uji Validitas}

Pengembangan alat ukur sit up berbsis teknologi digital ini divalidasi Ahli Elektro sebesar $88,8 \%$ maka alat ukur sit up berbsis teknologi digital dikatagorikan "Baik/Layak'.dDari hasil evaluasi atau penilaian Ahli Tes dan Pengukuran sebesar 94\% maka alat ukur sit up berbsis teknologi digital dikatagorikan"Baik/Layak"sebagai alat tes sit up.

\section{Uji Reliabilitas}

Pada penelitian ini peneliti melakukan uji reliabilitas dengan test dan retest yaitu metode ulang dengan dua kali uji coba. Uji coba pertama dan kedua memiliki rentang minimal satu hari setelah uji coba pertama dengan responden yang sama. 
Jika kedua data memiliki ke- samaan, berarti alat tersebut dapat dikatakan reliabel. Pengujian reliabilitas pada kelompok kecil melibatkan 10 orang sampel. Sementara itu, pengujian untuk kelompok besar melibatkan 20 orang sampel. Hasil dari setiap uji reliabiliatas dapat dilihat pada tabel 1.

\section{HASIL PENELITIAN}

Hasil Penelitian ini menghasilkan sebuah alat ukur sit up berbsis teknologi digital yang memiliki tingkat validitas dan reliabilitas yang baik Dengan demikian, reliabilitas Pengembangan alat ukur sit up berbsis teknologi digital adalah $0.995 \%$ untuk skala kecil dan 0.996\% untuk skala besar. Menurut Ali (2012:116), interpretasi secara sederhana terhadap angka indeks korelasi " $r$ " product moment ( $r x y$ ) reliabilitas Pengembangan alat ukur sit up berbsis teknologi digital berada pada kategori sangat kuat. Dengan demikian, dapat diketahui bahwa Pengembangan alat ukur sit up berbasis teknologi digital "Baik" digunakan sebagai alat tes sit up.

Cara Kerja alat ukur sit up berbasis teknologi digital
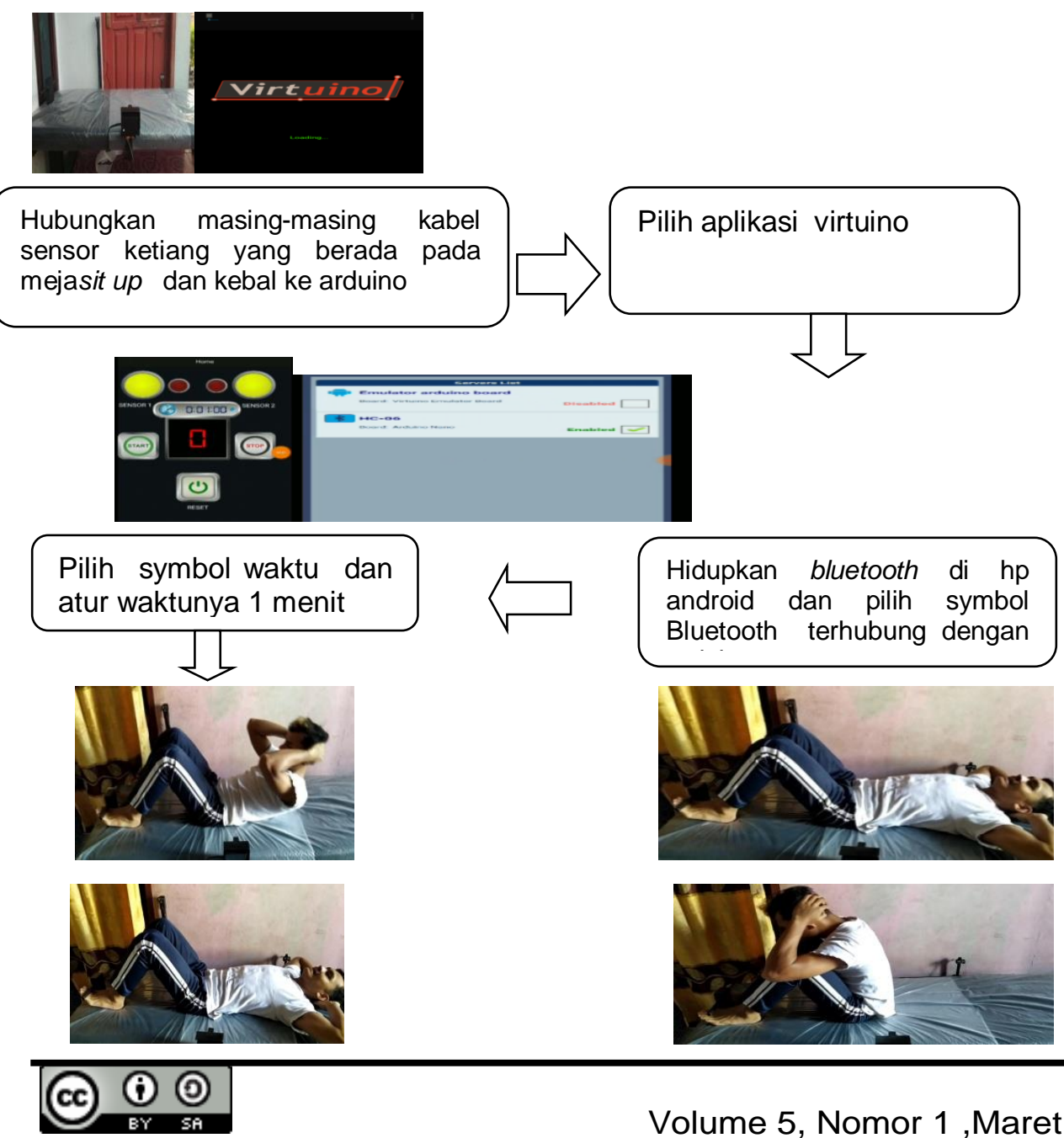

Volume 5, Nomor 1 ,Maret 2020 sportasaintika.ppj.unp.ac.id 


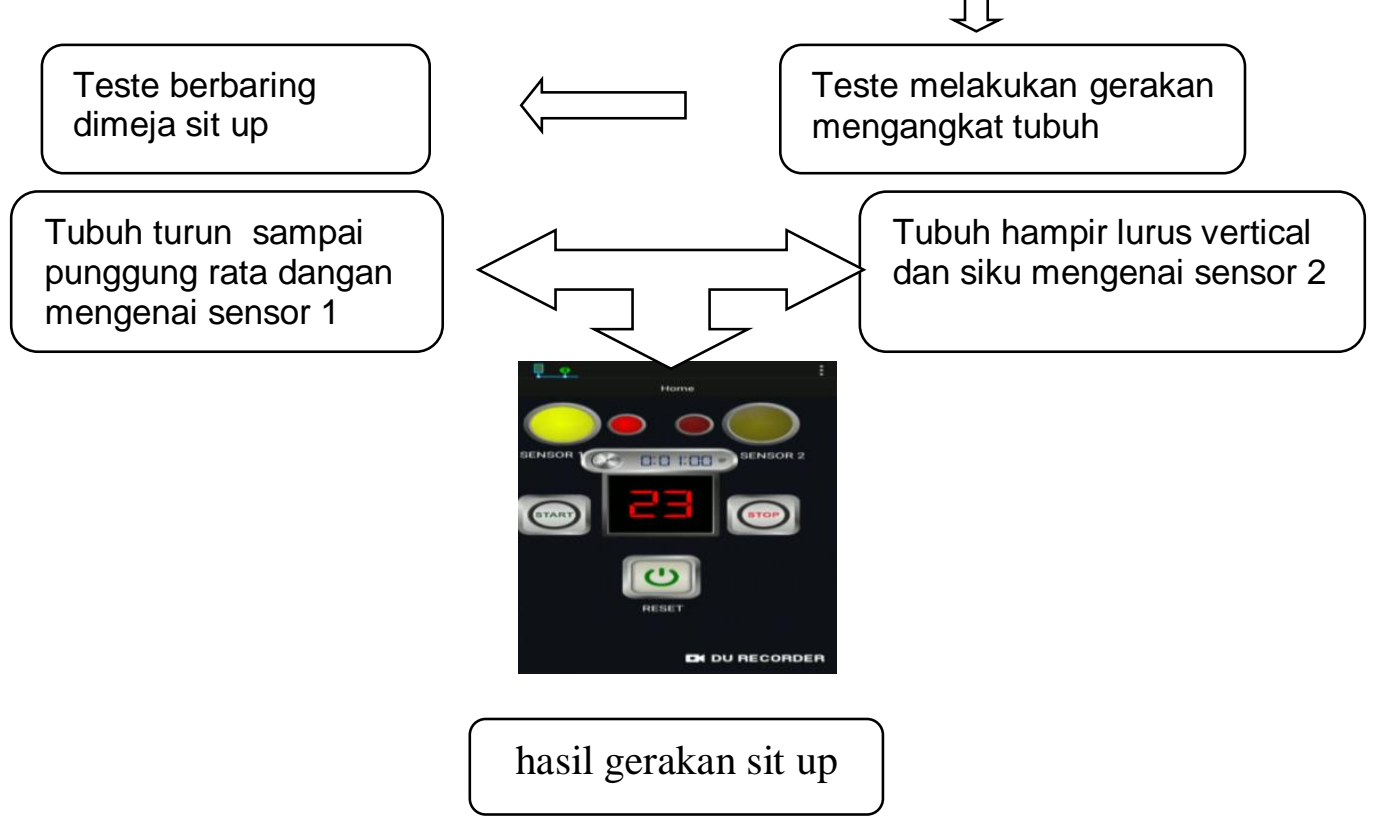

\section{PEMBAHASAN}

Pada awal pengembangan alat ukur sit up berbsis teknologi digital di desain dan diproduksi menjadi sebuah produk awal berupa alat ukur dalam tes dan pengukuran ke depan.Kualitas alat ini termasuk dalam katagori "layak" dari kedua ahli baik ahli Elektro dan Ahli Tes Dan Pengukuran, serta dalam penilaian uji coba kelompok kecil dan uji coba kelompok besar.

\section{Validitas Alat Ukur}

Validitas berasal dari kata validity yang berarti sejauh mana ketepatan dan kecermatan pengukur (tes) dalam melakukan fungsi ukurnya (Azwar, 2011). Validitas menunjukkan keadaan yang sebenarnya dan mengacu pada kesesuaian antara konstruk, atau cara seorang peneliti mengkon septualisasikan ide dalam definisi konseptual dan suatu ukuran. Hal ini mengacu pada seberapa baik ide tentang realitas "sesuai" dengan realitas aktual. Dalam istilah sederhana, validitas membahas pertanyaan mengenai seberapa baik realitas sosial yang diukur melalui penelitian sesuai dengan konstruk yang peneliti gunakan untuk memahaminya (Neuman, 2007). 
Tabel 1 nilai uji reliabilitas

\begin{tabular}{|ccc|}
\hline Kelompok & Hasil & Keterangan \\
\hline Kecil & 0.995 & Sangat kuat \\
\hline Besar & 0.996 & Sangat kuat \\
\hline
\end{tabular}

Cara Mengukur Validitas dengan mendefinisikan secara operasional konsep yang akan diukur sampai tersusun alat ukur atau kuesioner.

a. Uji coba

b. Tabulasi

c. Uji statistik dengan korelasi " Product Moment "

Pada penelitian ini peneliti menggunakan metode yang pertama yaitu metode uji coba alat yaitu uji coba kelompok kecil sebanyak 10 orang dan uji coba kelompok besar yaitu 20 orang, dan hasil uji coba tersebut di lakukan sebanyak tiga kali dalam sekali uji coba, dan hasil percobaan pertama dan percobaan kedua di olah dengan rumus korelasi produk momen untuk melihat validitas data pada uji coba pertama dan kedua.

Metode uji statistik dengan korelasi " Product Moment "yaitu melakukan pengambilan data sebanyak dua kali dan hasilnya diolah dengan rumus $r$ berikut:

Dari hasil perhitungan dengan rumus diatas, maka hasil data yang akan dicocokan menggunakan tabel interprestasi nilai r.Berdasarkan Interprestasi dari nilai $r$ menurut Husaini dan Purnomo (2006: 201), maka nilai $r$ dari uji coba kecil yang dilakukan alat adalah 0.995 dan kelompok kecil 0.996 . Nilai tersebut memiliki kategori reabilitas yang Tinggi.

2. Reabilitas Alat Ukur

Reliabilitas berasal dari kata reliability yang berarti sejauh mana hasil suatu pengukuran memiliki keterpercayaan, keterandalan, keajegan, konsistensi, kestabilan yang dapat dipercaya. Hasil ukur dapat dipercaya apabila dalam beberapakali pengukuran terhadap kelompok subjek yang sama diperoleh hasil yang relatif sama (Azwar, 2011).

a. Metode ulang

b. Metode responden sama, kuesioner (alat ukur) sama, penelitian dua kali

c. Stability Reliability Neuman (2000)

Pada penelitian ini peneliti melakukan uji reabilitas dengan teknik yang pertama yaitu dengan metode ulang yaitu dua kali uji coba, setiap uji coba dilakukan satu kali pengulangan. Uji coba pertama dan kedua memiliki rentan minimal satu hari setelah uji coba pertama dengan responden yang sama. Jika 
kedua data memiliki kesamaan, berarti alat tersebut dapat dikatakan reliabel.

\section{KESIMPULAN}

Penelitian dan pengembangan ini menghasilkan sebuah produk yaitu alat ukur tes sit up berbasis arduino dan sensor ultrasonik dengan aplikasi android yang dapat dijadikan.Dari hasil evaluasi atau penilaian Ahli Elektro sebesar 88,8\% maka alat ukur tes sit up berbasis arduino dengan aplikasi android dikatagorikan "Baik/Layak'.Dari hasil evaluasi atau penilaian Ahli Tes Dan Pengukuran sebesar 94\% maka alat ukur tes sit up berbasis arduino dan sensor ultrasonik denga aplikasi android dikatagorikan"Baik/Layak"sebagai alat tes kekuatan otot perut .

Alat ini mengunakan kabel sebagai fungsi komunikasi transfer data dari sensor ke arduino dan dari arduino ke android.Alat ini mengunakan meja sit up yang kerangka dari besi dan bantalan matras.Desain alat fitnes dan mudah untuk dibawa ketika berpindah tempat pengetesan. Alat ukur tes sit up berbasis teknologi digital untuk mengukur kekuatan otot perut selama 1 menit,sensor dapat diatur jaraknya setiap orang memiliki tinggi badan yang berbeda,makapenempatan sensor pun akan berbeda.

\section{DAFTAR PUSTAKA}

Ali, Mohammad. dan Mohammad Asrori. 2012. Psikologi Remaja Perkembangan Peserta Didik. Jakarta: PT. Bumi Aksara

Azwar, Saifuddin.Realibilitas dan Validitas.Yogyakarta:Pustaka Pelajar.

Husaini Usman dan Purnomo Setiady. 2006. Metodologi Penelitian Sosial. Jakarta : PT Bumi Aksara.

Nana Syaodih Sukmadinata. 2005. Metode Penelitian Pendidikan. Bandung: Remaja Rosda Karya.

Neuman, W. Lawrence. 2007. Basic of Social Reasearch : Qualitative and Quantitative Approaches, Pearson Education Inc, Boston.

Sugiyono. 2010. Metode Penelitian Kuantitatif, Kualitatif, dan R \& D. Bandung:

Undang-undang Republik Indonesia Nomor 3 (2005). Himpunan Peraturan Perundang-undangan Republik Indonesia Tentang Sistem Keolahragaan Nasional. Nuansa Aulia. 